\title{
The division of the genus Lepista
}

\author{
HARRI HARMAJA
}

HARMAJA, H. 1978: The division of the genus Lepista. - Karstenia 18: 49-54.

The genus Lepista (Fr.) W.G. Smith sensu Harmaja (Agaricales) is divided into two subgenera and seven sections. The subgenera are distinguished by the degree of spore wall cyanophily and different ability of the mycelium to produce nitrite in culture.

A short note is given on the responses of spores and basidia of Lepista to cotton blue and acetocarmine. Weakly carminophilic basidial granules are reported in some Lepista-like fungi for the first time.

Agaricus svaveolens $\mathrm{Fr}$. is considered a nomen dubium et confusum. One new species, Lepista albofragrans Harmaja, is described. The following five new sections are described: Lepista subg. Lepista sect. Gilva Harmaja, L. subg. Lepista sect. Nuda Harmaja, L. subg. Pseudolyophyllum sect. Fragrans Harmaja, L. subg. Pseudolyophyllum sect. Phyllophila Harmaja, and L. subg. Pseudolyophyllum sect. Metachroa Harmaja. The following two new infrageneric combinations are also made: Lepista subg. Pseudolyophyllum (Sing.) Harmaja, and L. subg. Lepista sect. Disciformes (Fr.) Harmaja.

Harri Harmaja, Botanical Museum, University of Helsinki, SF-00170 Helsinki 17, Finland

\section{Introduction}

On three previous occasions, I have amended the concept of the genus Lepista (Fr.) W.G. Smith (Agaricales) by the inclusion of species or species groups generally considered members of Clitocybe (Fr.) Staude (Harmaja 1969, 1974a and 1976a). (The palest fresh spore deposit in Lepista was given by me inexactly as 'pure white' in the latest paper. However, the exact expression for the colour in question, that of $L$. metachroa (Fr.) Harmaja, should be 'almost pure white: with an extremely faint yellow tinge'.) These transfers make it necessary to present a revised division of Lepista.

The genus Lepista has been discussed a great deal in the literature during recent years, and its delimitation has been the subject of some controversy. Bresinsky \& Schneider (1975) in a most interesting article reported a biochemical property of fungi with important taxonomic bearings, especially around Clitocybe. These authors studied a considerable number of species belonging to different groups of the Agaricales, and found that Lepista sensu Singer 1962, with six examined species, was the only larger genus invariably able to reduce nitrate, i.e. assimilate nitrate-nitrogen, in the culture medium. Almost $50 \%$ of the remaining nitratereducers belonged to Clitocybe as delimited in Singer (1962). Of the eight species of Clitocybe examined, three were non-reducers; all these, including the type of the genus C. gibba (Fr.) Kumm., were left in Clitocybe in my latest generic revision (Harmaja 1976a), whereas the five reducers were removed by me on non-biochemical grounds: Clitocybe gilva (Fr.) Kumm. coll., C. nebularis (Fr.) Kumm., C. odora (Fr.) Kumm. and C. diatreta (Fr.) Kumm. were transferred to Lepista (Harmaja 1969, 1974a, 1976a), and C. hydrogramma (Fr.) Kumm. was transferred to a new genus of its own, Singerella Harmaja (Harmaja 1974b). The results of Bresinsky and Schneider thus beatifully agree with the conclusions reached by me after evaluating completely different characters, and strongly support the above-mentioned revisions of the generic limits around Clitocybe.

Another point on which different views exist is the identity of the type species of Lepista, Agaricus lepista Fr. (not 'Paxillus lepista Fr.' as originally published, as Romagnesi 1976 believes). Singer's earlier suggestion (e.g. Singer 1962) that Lepista subaequalis (Britz.) Sing. was the same species was criticized because of the discrepancy between the modes of gill-attachment given for these species in their protologues. I myself (Harmaja 1974a) proposed L. subconnexa (Murr.) Harmaja. Recently Singer \& Clémençon (1972), Singer $(1975,1976)$ and Kühner (1976) expressed the opinion that $L$. densifolia (Favre) Sing. \& Clém. is A. lepista and is thus the correct name for the type species of Lepista. 
It is difficult to accept this view, because the type locality of $A$. lepista lies in Sweden, but $L$. densifolia (if, anyway, different from $L$. subconnexa) has not been found in Fennoscandia. As I have pointed out (Harmaja 1974a), L. subconnexa occurs in Fennoscandia, being known from Finland and Norway, and thus most probably also occurring in Sweden.

A group of species, some described under Clitocybe, others still undescribed, otherwise show the characters diagnostic of Lepista sensu Harmaja (1976a), but possess carminophilic granulation in their basidia. According to my type and other studies, the following species belong to this group: $C$. augeana (Mont.) Sacc., C. festiva Favre, $C$. festivoides Lamoure, C. microspora Peck, C. polygonarum Laursen, Miller \& Bigelow, and $C$. rubella Bigelow. Their generic position is puzzling; because of these granules I have refrained from transferring them to Lepista. On the other hand, they cannot be assigned to Lyophyllum Karst. or Calocybe Kühn. ex Donk, either, because their spore wall is carminophobic. Moreover, the carminophilic granules are smaller and stain more weakly than those of the species of the two last-named genera. The inconspicuousness of the granules partly explains why they have not been observed previously. It may be that the granules in these deviating species are not vesicles associated with the endoplasmic reticulum, or ERVs, as in Lyophyllum and Calocybe (Clemençon 1975), but some other organelles, such as lysosomes. I have the impression that these species are more closely related to Lepista species than to those of Lyophyllum or Calocybe. The diagnostic characters of Lepista may have to be amended in the future to include weakly carminophilic basidial granules. The creation of a new genus for these deviating species is not indicated at present.

My recent studies have revealed a few new features to be added or corrected to the diagnostic characters of Lepista presented earlier (Harmaja 1974a). Firstly, in the fair number of species examined so far, the spore walls are carminophobic. Secondly, the basidial walls are likewise carminophobic. Thirdly, in all the species studied for this character, such as $L$. cf. robusta (Peck) Harmaja and L. fragrans (Fr.) Harmaja, the basidial walls are very weakly (but undoubtedly) cyanophilic; according to my mostly unpublished observations, this response is not uncommon in the Agaricales, though it has previously been reported only for Tricholoma (Fr.) Staude (Harmaja 1976b). I have also found further species with the uninucleate spore observed by earlier workers, especially Kühner (1945).
One previous division of Lepista should be mentioned - that of Singer (1975). He divides the genus directly, i.e. without using the subgeneric category, into three sections: Lepista, 'Genuinae Konr. \& Maubl.' and 'Inversae Sing \& Clém.'. I consider his division taxonomically correct, but the last two names are illegitimate (see further). However, the species transferred to the genus by me (Harmaja 1974a, 1976a) necessitate the establishment of four additional sections and - in my opinion the division of the genus into two subgenera.

\section{The criteria used in the present division}

Among the criteria used to distinguish the sections of Clitocybe (including species later transferred to Lepista) were the hygrophany of the pileus, strong fragrant odour and spore size (Harmaja 1969). In the division of Lepista proposed below, I assign slightly less value to these characters, and consider that they may be diagnostic only at the subsectional level (which is not considered in the present division).

A difficult question is whether the genus in its latest circumscription (Harmaja 1976a) should be divided into subgenera or not. In my earlier studies (Harmaja 1974a, 1976a) it appeared that in some of the species the spore walls were strongly cyanophilic and, especially when young, frequently collapsed, while in the remainder the walls were only weakly cyanophilic and only a small number were collapsed. My later studies have shown that these differences are not always very sharp. In $L$. fragrans, $L$. odora and L. metachroides (Harmaja) Harmaja, at least, the spore wall may be moderately rather than weakly cyanophilic in some of spores in well-stained mounts. Likewise, in some collections of the group of species that has a weakly cyanophilic spore wall and that was transferred to Lepista most recently (Harmaja 1976a), the spore walls may be collapsed in a large proportion (even the majority) of the young attached spores. Moreover, my type studies indicate that the spore walls of $L$. aeruginosa (Bigelow) Harmaja and L. idahoensis (Bigelow) Harmaja are intermediate in their response to cotton blue, being best considered moderately cyanophilic. (This feature as well as the fact that I do not know these two species in the fresh condition and am thus no certain of the correctness of their reported spore colour made me exclude them from the present division.) Nevertheless, these two characters of the spore wall, especially the strength of the response to cotton blue, divides the species of Lepista sensu Harmaja (1976a) fairly clearly into two groups. But my final decision to recognize two subgenera was made after receiving the paper of 
Bresinsky \& Schneider (1975), which, besides establishing the presence of nitrate reductase in Lepista sensu Harmaja (1976a), also reports that $L$. odora and $L$. diatreta are differentiated from the remaining eight species by their ability to produce nitrite. These two species have a greater reducing capacity: their mycelia are able to produce nitrite not only in medium containing nitrate, like the others, but also in medium containing amino nitrogen as the sole nitrogen source. These biochemical results admittedly concern only a part of the species of Lepista, but they confirmed my planned subgeneric division, which was based on quite different characters, viz. the spore features.

The following proposal for a division of the genus Lepista is based on and contains only species familiar to me personally. However, they apparently represent the majority of the valid species at present known to belong to Lepista and also all the relevant taxonomic groups within the genus.

\section{Nomenclatural notes}

The sectional epithet 'Genuinae Konr. \& Maubl. 1924-1937', as cited and used in Singer's (1975 and previously) classification of Lepista, is inadmissible. The name was published originally as 'Rhodopaxillus Maire I. Genuini K. \& M.', i.e. as a taxon without the designation of rank, in the tenth and last fascicle of the general text to the 'Icones selectae fungorum' of Konrad and Maublanc. The taxon was described only in French, and as the publication in question, the fascicle 10, was published on April 30, 1937 (i.e., after January 1, 1935), the name 'Rhodopaxillus I. Genuini Konr. \& Maubl.' is illegitimate as having not been published validly. It may be mentioned that the work 'Révision des Hyménomycètes de France et des pays limitrophes', which is an extract of the general text of all the fascicles of the 'Icones selectae fungorum', gives December 1936 as the printing date of the 10th fascicle. On the other side, in the volumes containing the colour plates this date is given as April 30,1937 . This later date is no doubt the correct one since at the very end of the 'Révision' there are the figures '4-37' which most probably have been added by the printing shop to show the true date of printing. The mention about December 1936 was apparently a too optimistic preliminary estimate. In the present division, the section in question is designated sect. Nuda Harmaja, n. sect.

In the same fascicle no. 10 of the 'Texte général' a new subgenus to Lepista is described: 'Lepista sousgenre Eulepista K. \& M.'. However, for the same reason as the 'Genuini', this name is illegitimate as having not been published validly: the description of the taxon is only given in French and the date of publication is after January 1, 1935. Moreover, under the rules of the present 'Code', epithets beginning with the prefix 'eu-' are inadmissible, even if having been published validly originally. For the latter reason Singer \& Clémençon (1972) wished to create at the sectional level a new name for this taxon and proposed 'Lepista sect. Inversae Sing. \& Clém. nom. nov.', without any Latin. But also the name published by Singer and Clémencon is illegitimate as having not been published validly: an invalid name, such as 'Lepista subg. Eulepista', cannot serve as the basionym for a nomen novum. If Lepista gilva (Fr.) Roze coll. (incl. L. inversa) is considered worth of a subdivision of genus of its own, this subdivision has to be described as formally quite new, i.e. with a Latin description. I agree with Singer and Clémencon that the fungi in question deserve a section of their own and describe below Lepista subg. Lepista sect. Gilva Harmaja, n. sect.

Singer (1973) used my provisional sectional (not subsectional) name 'Clitocybe subg. Roseospora Harmaja sect. Odorae Harmaja ad int.' to serve as the basionym for a new combination in Clitocybe, and the resulting name is also used in Singer (1975). As my name, distinctly indicated as merely provisional, was of course not provided with a Latin description, the proposed new combination of Singer was not published validly, either.

\section{The division of the genus Lepista}

\section{Subgenus Lepista}

Basidiocarp large (mostly) to rather small, habit clitocyboid to tricholomoid, with very variable colours. Pileus hygrophanous or not, pruinose or not in the moist condition. Odour variable, rarely distinctly fragrant. Spores of very variable size, almost all to a small minority stick together to form tetrads and dyads in mounts of dried gills, a good proportion (usually the majority) of them, especially the immature ones, conspicuously collapsed; wall either verruculose in all spores (in most species), verruculose in some of the spores, or perfectly smooth in all spores, strongly cyanophilic including warts; contents probably always guttulate; in deposit pale pinkish buff or deep yellow. None of the eight species studied is able to produce nitrite from amino nitrogen. - Type: L. subconnexa (= Agaricus lepista $\mathrm{Fr}$. ).

\section{Section Gilva Harmaja}

Basidiocarp medium-sized, habit clitocyboid, colour 
throughout rusty yellow through fulvous and orangebrown to red-brown. Pileus hygrophanous or not, at least \pm pruinose. Odour like that of caraway. Spores very small, ca. $4.0-5.0 \times 3.0-4.0 \mu \mathrm{m}$, only a small minority in tetrads, subglobose to broadly ellipsoid; wall thick, verruculose in all spores with pronounced warts; in deposit pale pinkish buff. - Type: L. gilva. - Species: L. gilva (Fr.) Roze coll.

\section{Section Nuda Harmaja}

Basidiocarp large to small, habit \pm tricholomoid, blue, violet, lilac or purple colour present in at least some part when fresh, otherwise only brown colours present. Pileus hygrophanous, at least non-pruinose. Odour peculiar or indistinct but never strongly fragrant. Spores large, ca. 6.0-9.0 $\times 3.5-5.0 \mu \mathrm{m}$, a variable proportion in tetrads, ellipsoid or oblong; wall verruculose in all spores; in deposit pale pinkish buff. - Type: L. nuda. - Species: L. nuda (Fr.) Cooke, L. personata (Fr.) Cooke (if really distinct from the preceding species), L. sordida (Fr.) Sing.

\section{Section Lepista}

Basidiocarp large to medium, habit clitocyboid (mostly) to tricholomoid, colours white to brown and brown-grey. Pileus non-hygrophanous or hygrophanous, pruinose or not. Odour when fresh variable, rarely distinctly fragrant, often faintly sweetish when dry. Spores of very variable size, a variable proportion (usually the majority) in tetrads, ellipsoid or oblong; wall verruculose with differently sized warts either in all spores or, rarely, in a large part of them, the remainder being smooth; in deposit pale pinkish buff. - Type: L. subconnexa (= Agaricus lepista Fr.). - Species: L. fasciculata Harmaja, L. irina (Fr.) Bigelow, L. luscina (Fr.) Sing., L. polycephala Harmaja, L. subalpina (Bigelow \& Smith) Harmaja, L. subconnexa (Murr.) Harmaja.

\section{Section Disciformes (Fr.) Harmaja}

Basidiocarp large, habit clitocyboid to tricholomoid, colours white to grey-brown. Pileus not hygrophanous, at least pruinose. Odour indistinctly sweetish and turnip-like when fresh, often sweeter when dry. Spores large, ca. $6.0-8.5 \times 3.2-4.3 \mu \mathrm{m}$, the great majority in tetrads, ellipsoid or oblong; wall perfectly smooth in all spores; in deposit deep yellow. - Type: L. nebularis. - Species: L. nebularis (Fr.) Harmaja, L. robusta (Peck)Harmaja, L. singeri Harmaja.

\section{Subgenus Pseudolyophyllum (Sing.) Harmaja}

Basidiocarp small to medium, habit clitocyboid, colours variable. Pileus almost always hygrophanous, in one species non-hygrophanous, pruinose or not. Odour strongly to weakly fragrant or indistinct. Spores of very variable size, the majority (usually a large one) in tetrads, a variable proportion, mostly a minority, conspicuously collapsed; wall mostly perfectly smooth in all spores, rarely verruculose with very low pustules in probably all spores, weakly to moderately cyanophilic including the pustules; contents guttulate or homogeneous; in deposit pale pinkish buff, very pale yellow or almost pure white (extremely faintly yellow-tinged). Both the species studied are capable of producing nitrite from amino nitrogen. - Type: L. metachroa.

\section{Section Fragrans Harmaja}

Basidiocarp colour brown. Pileus hygrophanous, essentially non-pruinose. Odour strongly or weakly fragrant. Spores large, ca. 6.0-8.6 × 2.8-4.6 $\mu \mathrm{m}$; wall verruculose with very low pustules, probably in all spores; contents guttulate; in deposit pale pinkish buff. Membranal pigment probably always present in hyphae of pileus and gill trama. - Type: L. fragrans. - Species: L. fragrans (Fr.) Harmaja, L. harmajae (Lamoure) Harmaja.

\section{Section Phyllophila Harmaja}

Basidiocarp colour white, buff, almost flesh colour, pale brown or, rarely, greyish-green to glaucous and aeruginous. Pileus mostly hygrophanous, rarely nonhygrophanous, pruinose or not. Odour mostly weakly or strongly fragrant, in a few cases indistinct. Spores of variable size, mostly small; wall perfectly smooth in all spores; contents mostly homogeneous in all species but somewhat guttulate in some spores of some species; in deposit pale pinkish buff. Membranal pigment almost always absent from hyphae of basidiocarp. - Type: L. phyllophila. Species: L. agrestis (Harmaja) Harmaja, L. albofragrans Harmaja, L. diatreta (Fr.) Harmaja, $L$. marginella (Harmaja) Harmaja, L. odora (Fr.) Harmaja, L. phyllophila (Fr.) Harmaja, L. regularis (Peck) Harmaja (and several additional species, both those still hiding under Clitocybe and undescribed ones).

\section{Section Metachroa Harmaja}

Basidiocarp colour \pm dull: fuscous, grey-brown, brown-grey. Pileus hygrophanous, essentially non- 
pruinose. Odour indistinct or, at times in old fruit bodies, like that of Cystoderma carcharias, never fragrant. Spores large, ca. 5.5-9.5 × 3.2-4.8 $\mu \mathrm{m}$; wall perfectly smooth in all spores; contents guttulate; in deposit almost pure white (extremely faintly yellow-tinged) or very pale yellow. Membranal pigment always present in hyphae of basidiocarp. Type: L. metachroa. - Species: L. amarescens (Harmaja) Harmaja, L. metachroa (Fr.) Harmaja, L. metachroides (Harmaja) Harmaja.

\section{Latin descriptions}

Gilva Harmaja, n. sect. (Lepista subgenus Lepista). - Basidiocarpus cum colore gilvo, fulvo vel rufobrunneo. Pileus hygrophanus vel nonhygrophanus. Odor non fragrans. Sporae parvae ca. $4.0-5.0 \times 3.0-4.0 \mu \mathrm{m}$, plerumque singulares in preparatis e lamellis siccis factis, subglobosae vel late ellipsoideae, tunica incrassato distincte verruculoso, in cumulo roseae. - Typus: Lepista gilva (Fr.) Roze.

Nuda Harmaja, n. sect. (Lepista subgenus Lepista). - Basidiocarpus cum colore caeruleo, violaceo, lilacino vel purpureo. Pileus hygrophanus. Lamellae \pm sinuatae. Odor non gratus. Sporae magnae ca. $6.0-9.0 \times 3.5-5.0 \mu \mathrm{m}$, tunica verruculoso, in cumulo roseae. - Typus: Lepista nuda (Fr.) Cooke.

Fragrans Harmaja, n. sect. (Lepista subgenus Pseudolyophyllum). - Pileus hygrophanus. Odor fragrans. Sporae magnae ca. $6.0-8.6 \times 2.8-4.6$ $\mu \mathrm{m}$, tunica minutissime pustulato, intus guttulatae, in cumulo roseae. - Typus: Lepista fragrans (Fr.) Harmaja.

Phyllophila Harmaja, n. sect. (Lepista subgenus Pseudolyophyllum). - Pileus praecipue hygrophanus. Odor plerumque fragrans. Sporae magnitudo variabile, tunica perfecte laeve, intus plurimum eguttulatae, in cumulo roseae. - Typus: Lepista phyllophila (Fr.) Harmaja.

Metachroa Harmaja, n. sect. (Lepista subgenus Pseudolyophyllum). - Pileus hygrophanus, \pm fuscus. Odor non gratus. Sporae magnae ca. 5.5$9.5 \times 3.2-4.8 \mu \mathrm{m}$, tunica perfecte laeve, intus guttulatae, in cumulo subalbae vel subluteae. Typus: Lepista metachroa (Fr.) Harmaja.

Lepista subgenus Pseudolyophyllum (Sing.) Harmaja, n. comb. (Clitocybe subg. Pseudolyophyllum Singer, Ann. Mycol. 41: 41. 1943).

Lepista subgenus Lepista sectio Disciformes (Fr.) Harmaja, n. comb. (Agaricus [tribus] V. Clitocybe [turma] I. Disciformes Fries, Epicrisis Systematis mycologici: 55. 1836-1838).

\section{Lepista albofragrans Harmaja, n. sp.}

Pileus circa $1-4 \mathrm{~cm}$ latus, hygrophanus, pruinosus, non striatus, albidus disco non obscuriore. Odor fortis, gratus, ut in L. fragrans. Sporae ellipsoideae, $4.0-5.5 \times 2.6-3.4 \mu \mathrm{m}$, pariete laeve cyanophiloideo. Habitat extra silvam. - Typus: Finland, prov. Etelä-Häme, par. Lammi, Pappilankylä, Biological station of the University of Helsinki, sparse in arcs on lawn at eastern end of students' hostel, 12.IX.1975 Harri Harmaja (H).

Pileus ca. 1-4 cm broad, hygrophanous (rather weakly), white-pruinose, not translucent-striate when moist, ground colour below pruina uniformly whitish (faintly brownish), also very pale when dried: faintly brownish when dried slowly at low temperature but almost white (with some brownish or yellowish) when dried rapidly at high temperature, very low convex at first soon becoming plane and slightly and rather broadly depressed; margin inrolled for a long time; surface dry, glabrous, smooth when fresh but concentrically wrinkled when dry.

Stipe 2-5 $\times$ 0.3-0.6 cm, colouration approximately as in pileus, slightly but regularly enlarged towards base, often depressed; surface dry, glabrous; at the base some white cottony tomentum.

Lamellae shortly decurrent, whitish when fresh but assuming buff to yellowish-buff tinge on drying, close, thin, rather narrow, not forked or intervenose.

Odour, especially when drying, more or less strong, sweet, coumarine-like, similar to that of $L$. fragrans and L. odora; in dried basidiocarps no longer distinctly fragrant.

Taste mild, fungoid both when fresh and dry.

Spores (in Melzer's reagent unless otherwise indicated) $4.0-5.5 \times 2.6-3.4 \mu \mathrm{m}$, almost all in tetrads and dyads in mounts of dried gills, obtusebased, the great majority ellipsoid, the remainder slightly ovoid and oblong; wall smooth, hyaline, inamyloid and indextrinoid, weakly cyanophilic, carminophobic, \pm collapsed in roughly $50 \%$ of immature spores attached to sterigmata, but in only a minor proportion of released ones; contents mostly homogeneous, in a minority guttulate; uninucleate; in deposit pale pinkish buff, 9 B $2-9$ C $2-9$ D 2 (Maerz \& Paul 1950).

Basidia 13-18 $\times$ 4.0-5.5 $\mu \mathrm{m}$, four-spored, without carminophilic granulation.

Cystidia none of any kind.

Hymenophoral trama regular; clamp connections abundant, apparently present at every septum.

Epicutis of the common type, resembling that of, e.g., L. phyllophila (see Harmaja 1969). 
Ecology. Occurring singly or in arcs, among grass and mosses outside forest, in open, grassy, mostly man-made habitats, such as pastures, lawns and some rock outcrops. Substrate apparently nutrient-rich, composed of litter of grasses and herbs mixed with bare soil, or mull. Throughout September.

Distribution. Known up to altitudes slightly above $100 \mathrm{~m}$ in the hemiboreal and southern boreal zones (Ahti et al. 1968) in South Finland. Uncommon.

Specimens examined. Finland. Varsinais-Suomi: Lohja rural commune, Osuniemi, on fertile ground on rock outcrops, u.c. Clitocybe strigosa, 20.IX.1975 Harmaja (H). - Etelä-Häme: Lammi, Evo, Vahtervehmas, in pasture, 3.IX.1974 Tuomikoski (H). Lammi, Pappilankylä, 12.IX.1975 Harmaja (H, holotype).

Discussion. This new species will be - and surely has been - confused especially with the common species $L$. fragrans (Clitocybe fragrans) because of its pale-coloured strongly fragrant fruit bodies. However, even on superficial examination the two species can be distinguished from each other both with the bare eye and microscopically. In the moist condition, the pileus of $L$. albofragrans is whitish throughout, pruinose, and without translucent striation, but when moist the cap of $L$. fragrans is pale brown with a more or less darker disc, nonpruinose, and conspicuously translucent-striate (seeHarmaja 1969). In addition, the spores of $L$. fragrans are distinctly larger, measuring 6.2-8.6 $(-10.0) \times 3.4-4.6 \mu \mathrm{m}$, which is useful for identifying faded basidiocarps. L. phyllophila and $L$. regularis are rather similar to the new species but differ in their (1) fleshier fruit bodies (especially the former), (2) weaker and apparently somewhat different odour (especially the former), (3) slightly larger spores, and (4) forest habitat. L. agrestis is superficially very similar to $L$. albofragrans and also shares the habitat of the latter, but can be recognized mainly by its non-pruinose more or less translucentstriate cap and the lack of fragrant odour. Clitocybe anisata Velen. is, for the time being, an enigmatic species; it may be related to $L$. albofragrans but differs in the conspicuously distant and broad lamellae, emphasized in its protologue. (In 1969 I reported it, though with hesitation, from Fennoscandia. However, at present I consider that the specimens then referred to $C$. anisata should be regarded undeterminable for the time being, and that Velenovský's species should be deleted from the list of Fennoscandian fungi.)

The protologue of Agaricus svaveolens Fr. (not 'Schum. ex Fr.' since Fries stated that Schumacher's fungus differed from his!) sounds descriptive of $L$. albofragrans. However, Fries included $A$. svaveolens in a group containing non-hygrophanous fungi, and the stipe was described as different (stouter) from that of $L$. albofragrans. Fries may have been in possession of the albino form of $L$. odora when creating that binomial. Anyway, unlike the protologue of $A$. fragrans Sow. ex Fr., that of $A$. svaveolens is impossible to reinterpret afterwards, and since the name 'Clitocybe suaveolens (Fr.) Kumm.' has also been used in different senses, usually even in contradiction to the protologue, $A$. svaveolens $\mathrm{Fr}$. is best considered a nomen dubium et confusum.

L. albofragrans should be placed in subg. Pseudolyophyllum sect. Phyllophila (see above), in the neighbourhood of L. phyllophila.

Acknowledgements. Financial support for the study was obtained from the foundation 'Jenny ja Antti Wihurin Säätiö', which is greatly appreciated. Dr. Pekka Isoviita was helpful in nomenclatural matters.

\section{References}

Ahti, T., Hämet-Ahti, L. \& Jalas, J. 1968: Vegetation zones and their sections in northwestern Europe. Ann. Bot. Fennici 5: 169-211.

Bresinsky, A. \& Schneider, G. 1975: Nitratreduktion durch Pilze und die Verwertbarkeit des Merkmals für die Systematik. - Biochem. System. Ecol. 3: 129-135.

Clémencon, H. 1975: Ultrastructure of hymenial cells in two boletes. - Beih. N. Hedwigia 51: 93-98, pls. $20-23$.

Harmaja, H. 1969: The genus Clitocybe (Agaricales) in Fennoscandia. - Karstenia 10: 5-168.

- " - 1974a: A revision of the generic limit between Clitocybe and Lepista. - Karstenia 14: 82-92.

- " - 1974b: Singerella n. gen., a separate genus for Clitocybe hydrogramma. - Karstenia 14: 113-115.

- " - 1976a: A further revision of the generic limit between Lepista and Clitocybe. - Karstenia 15: 13-15.

" - 1976b: The walls of the spores and basidia of Tricholoma found to be cyanophilic. - Karstenia 15: $23-24$.

Kühner, $\mathbb{R}$. 1945: Nouvelles recherches sur les divisions nucléaires dans la baside et les spores des Agaricales. C.R. Acad. Sci. 220: 618-620.

- " - 1976: Agaricales de la zone alpine. Lépistées. Bull. Soc. Mycol. France 92: 5-32.

Maerz, A. \& Paul, M.R. 1950: A dictionary of color. Ed. 2. -208 pp., 56 pls. New York

Romagnesi, H. 1976: A propos du Paxillus lepista Fr. Bull. Soc. Mycol. France 92: 129-134.

Singer, R. 1962: The Agaricales in modern taxonomy. Ed. 2. - 915 pp., 73 pls. Weinheim.

- " - 1973: Diagnoses fungorum novorum Agaricalium 3. Beih. Sydowia 7: 1-106.

- " - 1975: The Agaricales in modern taxonomy. Ed. 3. 912 pp., 84 pls. Vaduz.

- " - 1976: Le genre Lepista et la nomenclature correcte. Bull. Soc. Mycol. France 92: 127-128.

Singer, R. \& Clémencon, H. 1972: Notes on some leucosporous and rhodosporous European agarics. N. Hedwigia 23: 305-344, pls. 1-7. 